\title{
Long-term fish monitoring underlines a rising tide of temperature tolerant, rheophilic, benthivore and generalist exotics, irrespective of hydrological conditions
}

\author{
Marco MILARDI, ${ }^{*}$ Mattia LANZONI, Anna GAVIOLI, Elisa Anna FANO, Giuseppe CASTALDELLI \\ Department of Life Sciences and Biotechnology, University of Ferrara, V. Luigi Borsari 46, 44121 Ferrara, Italy \\ *Corresponding author: marco.milardi@unife.it
}

\begin{abstract}
The invasion of exotic species is one of the main threats to worldwide biodiversity and can be aided by changes in environmenta conditions. We hypothesized that a temporal trend of decreasing discharge and increasing temperature might have favored the invasion of warm-adapted, lentic exotic fish species in the lower Po River, northern Italy. We used presence/absence data over a long-term period (over 20 years) to investigate the dynamics of exotic fish invasion along water temperature and discharge gradients. Mean annual discharge and temperature did not show a clear trend and did not affect exotic fish species invasion, which progressed with time irrespective of these factors. The total number of species fluctuated without a clear trend, which underlined a progressive substitution of native species with exotic ones. Perhaps surprisingly, the community composition changed over time towards more temperature tolerant but also rheophilic, benthivore and generalist fish species. These results highlight how species interactions could be one of the main factors driving the invasion. Furthermore, our data underlines a continuously rising tide of exotics, which questions the success of past control strategies. Considering the current conservation resources limitations, priority should be given to the development of prevention strategies in order to avoid new species introductions.
\end{abstract}

Key words: Presence/absence data; discharge; water temperature; exotic species; native species; exclusion rate.

Received: December 2017. Accepted: February 2018.

\section{INTRODUCTION}

Species invasions (i.e. the establishment and spread of exotic species) are undoubtedly one of the main factors affecting biodiversity worldwide (Leprieur et al., 2008). It has been widely reported that environmental factors could favor the invasion of certain species (Moyle and Light, 1996a), but it is not yet clear what the magnitude of these effects would be and whether they will equally affect all groups. Some studies have proposed that increased global temperatures could exacerbate the effects of species invasion by allowing the colonization of areas previously unsuitable for exotic species (Hellmann et al., 2008; Rahel and Olden, 2008). This could hold particularly true for poikilotherms, as they depend on external temperature more than omeotherms. Hydrological conditions could also favor the invasion of aquatic species, by providing flow conditions that are more suitable to exotics than natives (Moyle and Light, 1996b; Bunn and Arthington, 2002) but also the opposite can occur (Leprieur et al., 2006). However, since temperature or hydrological trends can be very subtle to detect in aquatic environments (Woodward et al., 2010), to perform such an investigation the availability long-term environmental data is of fundamental importance.
Most research on aquatic invasions has focused on their relatively short-term effects (usually $<5$ years), while the long-term (usually $>10$ years) dynamics of the invasion processes are still relatively unexplored (Strayer et al., 2006). This is partly due to the fact that exotic species research is a relatively young branch of ecology, so that long-term specific sampling programs have rarely been put in place. However, aquatic systems are especially challenging to sample, as monitoring usually involves higher equipment costs than terrestrial ecosystem sampling. Currently, it is still logistically and financially hard to collect long-term data on an invasion process, therefore the possibility to use data collected for other purposes, as long as suitable for analysis, should always be embraced.

Italy is particularly data-deficient, since fish introductions (i.e. the deliberate or accidental release of an exotic species in a new area) have been recorded (Bianco, 1998, 2014) but the dynamics and outcomes of their invasions have been rarely thoroughly analyzed (with few exceptions, see e.g. Castaldelli et al., 2013; Milardi et al., 2018). Yet Italian freshwaters could be a prime model to investigate aquatic invasions: recent studies have underlined that hotspots of exotic fish invasions are present in the Po River drainage in Northern 
Italy (Lanzoni et al., 2018) and that in this area exotic species play a strong role in shaping the abundance and distribution of native communities even after several years from initial invasion (Milardi et al., 2018). It has been previously hypothesized that current distributions, with native species inhabiting smaller streams at higher elevations, are mainly due to exotic species being better adapted to warmer and more lacustrine conditions (Bianco and Ketmaier, 2001), thus outcompeting natives in the lower stretches of rivers through better adaptation. However, most recent studies utilized short-term data, albeit spatially wide, and tried to resolve the results of the invasion rather than its temporal evolution.

Utilizing data on fish presence and absence in the lower stretch of the Po River, collected over a long-term (over 20 years), we attempted to investigate the broad dynamics of the latest exotic fish invasions in this area. We selected this river stretch because most fish introductions in this watershed date back to the 1970s and no major habitat alteration has taken place in the last 20 years, thus allowing to analyze the outcomes of interactions and dispersal dynamics with less confounding factors. We hypothesized that a temporal trend of decreasing discharge and increasing temperature could have favored the invasion of lacustrine exotic fish species, which are adapted to warmer waters. We investigated the variation through time in both native and exotic species ecofunctional traits with the aim to detect temporal trends in community composition. We also used linear and multimetric statistical tests to analyze the relationship between species presence, river discharge and temperature. We finally examined the relationship between all species through co-occurrence analysis, and between exotic and native species through nestedness analysis.

\section{METHODS}

\section{Study area}

The Po River is the largest (average discharge 1540 $\mathrm{m}^{3} \mathrm{~s}^{-1}$ ) and longest river in Italy (maximum distance 682 $\mathrm{km}$ ) flowing from the northwestern Alps into the Adriatic Sea, through all northern Italy. Near the Po River delta lies the province of Ferrara $\left(2600 \mathrm{~km}^{2}\right)$, which has an extensive agricultural land use supported by a canal network of more than $4000 \mathrm{~km}$ and a mean canal density of 1.53 linear $\mathrm{km}$ of canals per $\mathrm{km}^{2}$ of land. From the Po River, water is abstracted and enters this irrigation canal network through water abstraction plants. These plants draw water from the river using siphons, which are opened and closed according to irrigation needs. We collected fish samples for this study from the sedimentation basin of the Berra plant, a concrete basin of $60 \times 30 \mathrm{~m}\left(1800 \mathrm{~m}^{2}\right)$ and $3 \mathrm{~m}$ deep, with the purpose to avoid siltation of the canals. The basin is fed water through 4 siphons with a diameter of $2 \mathrm{~m}$ (without grids), which abstract water by gravity from the lower stretch of the Po River. The water in the basin reaches an irrigation canal through other four siphons (equipped with $5 \times 5 \mathrm{~cm}$ grids) and enters the canal network, from where it is distributed for irrigation to the north-eastern part of Ferrara Province (Fig. 1).

Siphons are progressively opened between April and March, raising the water level in the sedimentation basin. Siphoning plants let little water through during winter (October-April), thus the water level in the basin is low throughout these months. During spring and through summer, the siphons act as a one-way suction sampler for fauna of the Po River that is close enough to be captured in the siphon suction. Given the diameter of a siphon, fish of all sizes are effectively transported from the river to the sedimentation basin from where individuals cannot return to the Po River due to the strong flow at the siphon. Moreover, with the exception of some small sized individuals $<10 \mathrm{~cm}$, the metal grill at the downstream siphons prevents downstream movement as well. Fish escape downstream was also blocked by the action of water pumps, engaged when there was a negative difference between the basin and the canal water levels. These barriers also prevented fish from the irrigation canal network from entering in the basin. During autumn and winter, the water level in the sedimentation basin drops and the basin becomes completely isolated from both the main river and the canal network, effectively trapping all the fish within.

\section{Fish data collection}

In order to remove the sediment that accumulated during the spring and summer, the Water Management Authority (Consorzio di Bonifica Pianura di Ferrara) completely removed all fish trapped in the basin at the beginning of each autumn (usually October) using seine nets, $1.5 \mathrm{~m}$ in height with a $25 \mathrm{~m}$ mouth and a knot-toknot mesh size of $8 \mathrm{~mm}$ and landing nets, with a knot-to-knot mesh size of $4 \mathrm{~mm}$. Fish were captured in repeated passes and brought up from the basin bottom by using mechanical cranes. At the complete emptying of the basin no specimens were left inside. All fish were identified (according to Kottelat and Freyhof, 2007) and subsampled before being released back into canals where a suitable water level allowed them to survive. Fish species were either classified as exotic (i.e. introduced by human action) or native (i.e. native to the Po River watershed, including its delta) according to the latest available information.

We used fish presence/absence data from these operations, collected from 1994 to 2016, to build a matrix 
of species occurrence through the years that would be representative of the fish fauna of the lower stretch of the Po River (indicatively from the last tributary, the Panaro River about $40 \mathrm{~km}$ upstream of the Berra plant, to the river delta, about $30 \mathrm{~km}$ downstream). Unfortunately, fish data were not available for years 2002 and 2010 .

\section{Hydraulic and thermal data}

Hydrological data on the discharge and temperature of the Po River were taken from the Regional Agency for Prevention, Environment and Energy of Emilia-Romagna (Agenzia regionale per la prevenzione, l'ambiente e l'energia dell'Emilia-Romagna - ARPAE), at a section close to the Berra plant. Since no tributary or water diversion is present between this section and the plant, the discharge and temperature were representative of the stretch of the main river near the plant. We used this data to calculate mean annual discharges and mean annual temperatures for the period 1994-2016 (discharge was not available for years 2002 and 2010 whereas temperature was not available for 2006).

Daily discharge at the Berra plant was obtained from the Water Management Authority, which controls the water abstraction for irrigation purposes. We used this data to evaluate whether interannual variations in water abstraction timing and magnitude could be a disturbing factor in the analysis, using the mean abstraction and its standard deviation in a 6-years period (2011-2015). We also checked that data from this period would be representative for the whole time series (Water Management Authority, personal communication).

\section{Species ecofunctional traits characterization}

We characterized some ecofunctional traits of all fish species sampled (Milardi and Castaldelli, 2018), with the aim of identifying variations of community composition through time. Fish species were divided into ecofunctional guilds using the information from continuously updated online databases such as FishBase (Froese and Pauly, 2017) or Freshwaterecology.info (Schmidt-Kloiber and Hering, 2015), or through peer-review papers when available. When no information was available expert knowledge was used to fill the gaps, usually assuming that the species would share ecofunctional characteristics with the closest related species for which information was available.

Within the first guild, fish were either identified as rheophils (preferring fast flowing water), limnophils (preferring slow or no current) or eurytopic (having no

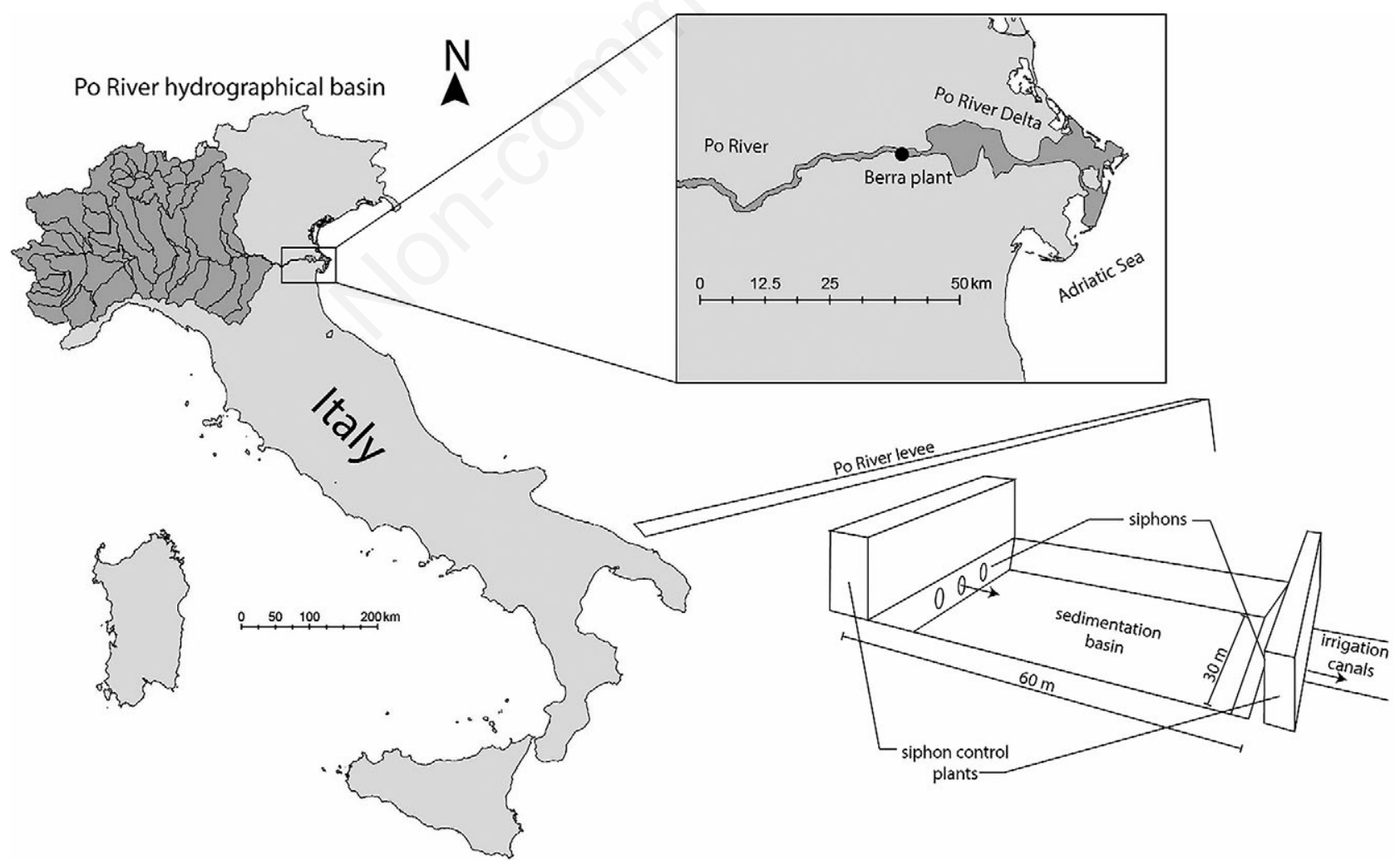

Fig. 1. Map of the study area: sampling location in the upstream section of the Po Delta (Province of Ferrara, Italy), in the Berra plant. 
particular preference). Within the second guild, fish species were divided into two mutually excluding categories of tolerance/intolerance to high temperature (indicatively above $20^{\circ} \mathrm{C}$ ). We finally used a feeding ecological function, where we considered the prevalent diet of adult individuals for the definition of categories. This was because most fish species have rather wide trophic niches and exhibit ontogenetic diet shifts. Fish were divided into herbivores (exhibiting specific adaptations for plant feeding, such as pharyngeal teeth), benthivores (exhibiting specific adaptations for bottom feeding, such as downturned mouths or barbels), invertivores (specifically adapted to or predating prevalently on insects and other invertebrates), piscivores (with specific adaptations for feeding largely on fish), and generalists (with unspecialized mouthparts and digestive systems, feeding on a broad range of items).

\section{Data analysis}

We used the Spearman rank test to investigate the presence of long-term correlations in mean annual discharge and temperature or number of species and share of exotic species. We further used the linear regression to identify the exact relation between variables when a correlation was found. These analyses were performed using R software (R Core Team, 2017).

To assess the multivariate relationships among fish species, abiotic parameters (discharge and water temperature) and years of sampling, we considered fish species as dependent variables and abiotic parameters and years as independent ones. We used a Detrended Correspondence Analysis (DCA), in order to select the most appropriate response model for gradient analysis (Ter Braak and Smilauer, 2002; Lepš and Šmilauer, 2003). As a result of DCA, the dominant gradient length was lower than 3 and therefore we chose a Redundancy Analysis (RDA). These analyses were performed using the CANOCO 4.5 for Windows software (Lepš and Šmilauer, 2003).

We tested for patterns of community co-occurrence using each year as a replicate community, without specific assumptions on exclusion patterns due to interspecific competition for shared resources (Connor and Simberloff, 1979), as there are multiple other forms of interactions possible among species (e.g. predator/prey). Cooccurrence analysis was performed using $\mathrm{R}$ software ( $\mathrm{R}$ Core Team, 2017) and the "EcoSimR" package 0.1.0 (Gotelli et al., 2015). This analysis provides a so-called $\mathrm{C}$-score index (both simulated and observed) which could be used to assess the level of co-occurrence by comparing it to other datasets (see e.g. Gotelli and Ulrich, 2010; Gotelli et al., 2015). However, this metric does not distinguish between native or alien species; a low C-score (usually below 10) indicates that species are overall aggregated and its variance and skewness indicate the degree of heterogeneity in the $\mathrm{C}$-scores of the different species and absence of outlier pairs that are highly segregated (positive skewness) or highly aggregated (negative skewness), respectively.

In order to quantify the degree of nestedness of fish species assemblages during the period, we used the BINMATNEST software (Rodríguez-Gironés and Santamaría, 2006). Generally, the BINMATNEST provides the nestedness temperatures of the fish populations but in this study, it was used to estimate two types of rankings through the final packed matrix: the ranking of species based on their nesting capacity and the ranking of years based on species population nestedness.

\section{RESULTS}

\section{Discharge and temperature as factors for the invasion}

Mean annual discharge and temperature were negatively correlated with each other, albeit poorly (Spearman rank coefficient $\mathrm{P}<0.05$, Discharge $=5234.66$ (237.51×Temp), Rsqr=0.18). Both discharge and temperature were poorly correlated with time (Spearman $\operatorname{rank} \mathrm{P}=0.352$ and $\mathrm{P}=0.611$, respectively); it was therefore impossible to define a clear temporal pattern or trend for these two variables (Fig. 2).

Water abstraction at the Berra plant was rather uniform in timing and magnitude, with a mean annual abstraction of $16,810,720 \mathrm{~m}^{3}$ year ${ }^{-1}$ between 2011 and 2015 (S.D. 2,586,945 $\mathrm{m}^{3}$ year $^{-1}$ ).

A matrix of presence/absence for all the fish species found in Berra over the study period was used to further analyze long-term trends in exotic and native species (Supplementary Tab. 1). This matrix also details common and scientific names of all fish species in this study, as well as their ecofunctional traits in term of temperature, flow preference and trophic ecology.

A significant increase in the share of temperature tolerant ( $v s$ temperature intolerant) species was observed through the period (Spearman Rank $\mathrm{P}<0.01, \%$ of temperature tolerant species $=-1300.27+0.69 \times$ Year, $\mathrm{Rsqr}=0.53$, Fig. 3a). There was also a significant increase in the share of rheophilic species ( $v s$ limnophilic species) over the period (Spearman Rank $\mathrm{P}<0.01, \%$ of rheophilic species $=-1286.54+0.65 \times$ Year, Rsqr $=0.45$, Fig. 3 a), while eurytopic species did not show a significant change (Spearman rank $\mathrm{P}=0.61$ ). Finally, among trophic guilds, a decrease in the share of invertivores and an increase in the share of generalists were detected (Spearman Rank $\mathrm{P}<0.01$ for all, and $\%$ of invertivores $=3025.81-1.50 \times$ Year, Rsqr $=0.72, \quad \% \quad$ of generalists $=1536.24+0.78 \times$ Year, Rsqr $=0.44$, Fig. 3b). An increase in the share of benthivores was also detected (Spearman Rank $\mathrm{P}<0.01$, 
$\%$ of benthivores $=-995.15+0.51 \times$ Year, $R$ sqr $=0.32$ ), albeit less marked, while other guilds did not show significant trends (Spearman Rank $\mathrm{P}=0.58$ and 0.13 for herbivores and piscivores, respectively).

The total number of fish species within the period was overall fairly stable, did not correlate with mean annual river discharge (Spearman rank $\mathrm{P}=0.30$ ) and did not show a trend over time (Spearman rank $\mathrm{P}=0.31$, Fig. $4 \mathrm{a}$ ). Conversely, the share of exotic species showed a clear and significant increase over time (Spearman rank $\mathrm{P}<0.01, \%$ of exotic species $=-4016.76+2.04 \times$ Year, Rsqr $=0.85$, Fig. $4 b$ ).

The share of exotic species on the total number of species was not related to either temperature or discharge (Spearman rank $\mathrm{P}=0.52$ and $\mathrm{P}=0.45$, respectively, Fig. 5).

The results of RDA analysis confirmed that time was the main factor affecting the presence of native fish in the species assemblage (Fig. 6).

\section{Relationship between exotic and native fish}

There was a relatively high co-occurrence of species through the years, with an observed C-score of 8.46 and a mean simulated $\mathrm{C}$-score of 7.25 (variance $>0.01$ ). There was no significant skewness in the metric. Nestedness

(a)
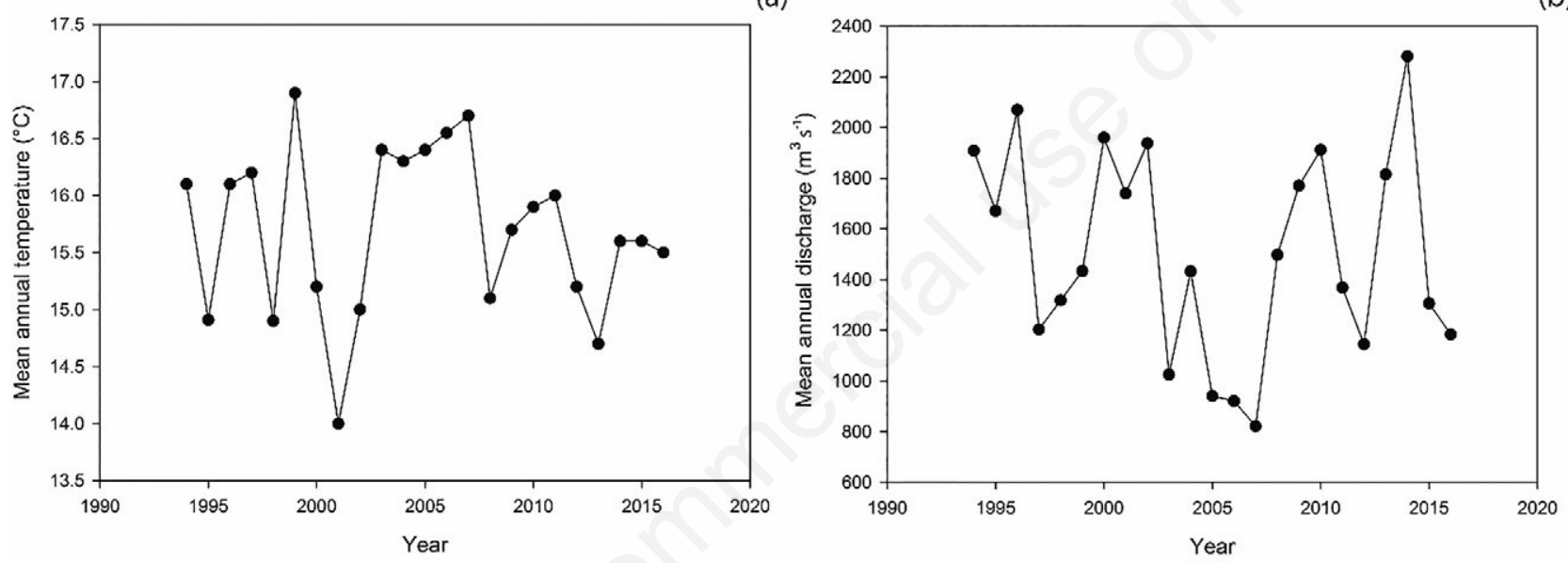

(b)

Fig. 2. Mean annual temperature (a) and discharge (b) trends over the study period.

(a)

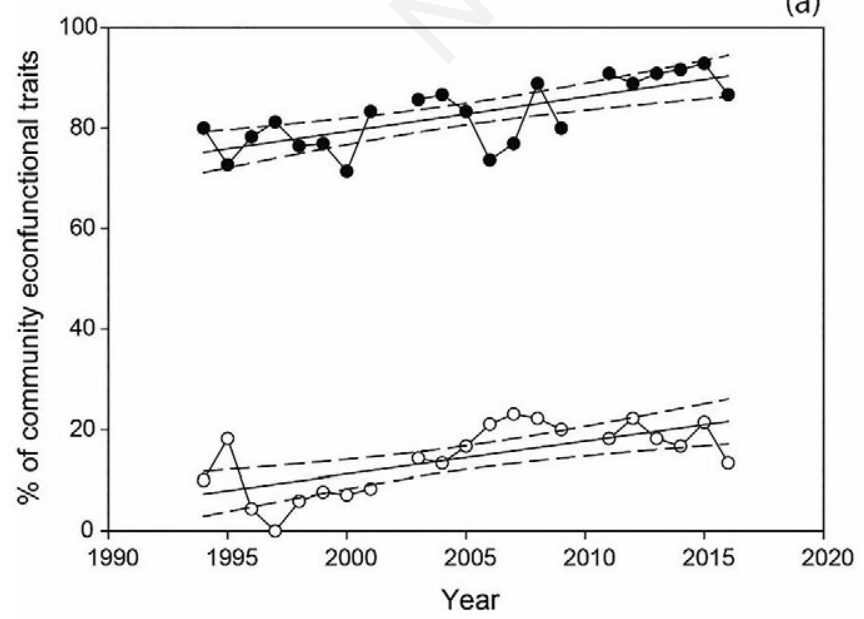

(b)

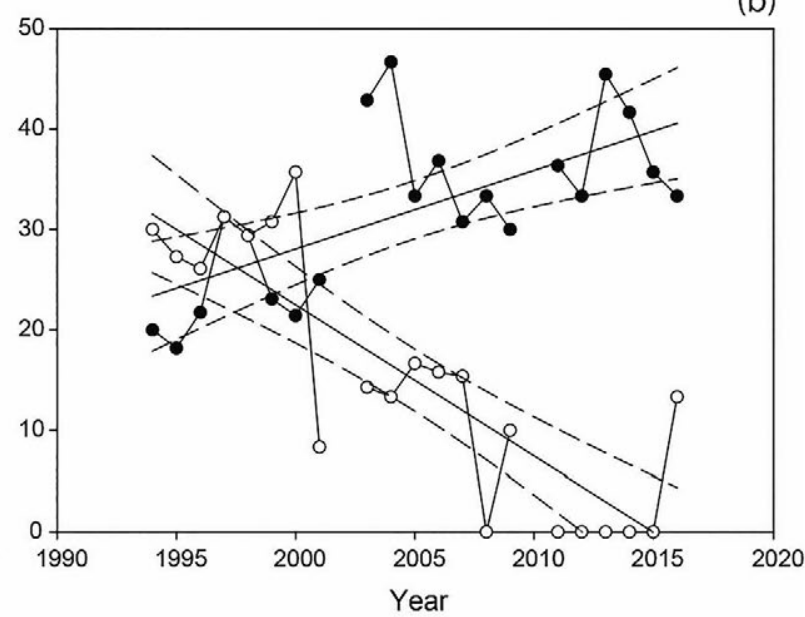

Fig. 3. Significant long-term trends in ecofunctional traits of the fish community of the lower Po River. A rising share of temperature tolerant (black circles) and rheophilic species (white circles) (a), corresponded to a decline in invertivores (white circles) and an increase in generalists (black circles) (b). The solid lines represent significant linear regressions while the dashed lines represent $95 \%$ confidence intervals. 
analysis indicated that native species were most nested at the beginning of the time series while exotic species were mostly nested in the latter years (Tab. 1). Overall species nestedness was conversely more variable with years 2006 and 2015 ranking in the first positions together with 1996 and 1997 (Tab. 1). Among native species, Anguilla anguilla (Linnaeus, 1758), Liza ramada (Risso, 1827) and Squalius squalus (Bonaparte, 1837) were the most nested while Platychthys. flesus (Linnaeus, 1758), Esox cisalpinus, Bianco \& Delmastro, 2011, and Tinca tinca (Linnaeus, 1758) the least nested (Tab. 2). Among exotic species, Cyprinus carpio, Linnaeus, 1758, Carassius spp. and Silurus glanis, Linnaeus, 1758, were the most nested while Micropterus salmoides (Lacépède, 1803), Ameiurus melas (Rafinesque, 1820) and Misgurnus anguillicaudatus (Cantor, 1842) the least nested (Tab. 2). Overall, A. anguilla, C. carpio and Carassius spp. were present in nearly all years (Tab. 2).

\section{DISCUSSION}

Prior to this study, not much was known about the fish communities of the lower Po River or their long-term dynamics. Contrarily to our initial hypothesis, it was evident from our data that exotic fish species invasion progressed with time irrespective of environmental factors such as discharge or temperature, which had no clear trends over the long term. Ecofunctional traits of the fish community shifted towards a larger share of temperature tolerant, rheophilic, generalist and benthivore species, while invertivores declined. Our data also confirmed that the overall exclusion rate was low, but this was probably because there was a progressive substitution of native with exotic fish, whereas the total amount of species was fairly stable. With few exceptions, native species were

Tab. 1. Nestedness of different years as derived from the presence of native, exotic and all species.

\begin{tabular}{llll} 
Nestedness order & Native & Exotic & Overall \\
\hline 1 & 1996 & 2006 & 1996 \\
\hline 2 & 1998 & 2015 & 2006 \\
\hline 4 & 1999 & 2016 & 1997 \\
\hline 5 & 1997 & 1996 & 2015 \\
\hline 6 & 2000 & 2004 & 1998 \\
\hline 7 & 2006 & 2003 & 2004 \\
\hline 8 & 1995 & 2007 & 2007 \\
\hline 10 & 2007 & 1997 & 2003 \\
\hline 11 & 2001 & 2014 & 2016 \\
\hline 12 & 2003 & 1998 & 2000 \\
\hline 13 & 2004 & 2011 & 1999 \\
\hline 14 & 1994 & 2000 & 2001 \\
\hline 15 & 2016 & 2013 & 1995 \\
\hline 16 & 2005 & 2005 & 1994 \\
\hline 17 & 2009 & 2012 & 2014 \\
\hline 18 & 2013 & 2001 & 2005 \\
\hline 19 & 2011 & 2009 & 2013 \\
\hline 20 & 2015 & 2008 & 2011 \\
\hline 21 & 2008 & 1995 & 2009 \\
\hline & 2014 & 1994 & 2008 \\
\hline 2012 & 1999 & 2012 \\
\hline
\end{tabular}

(a)

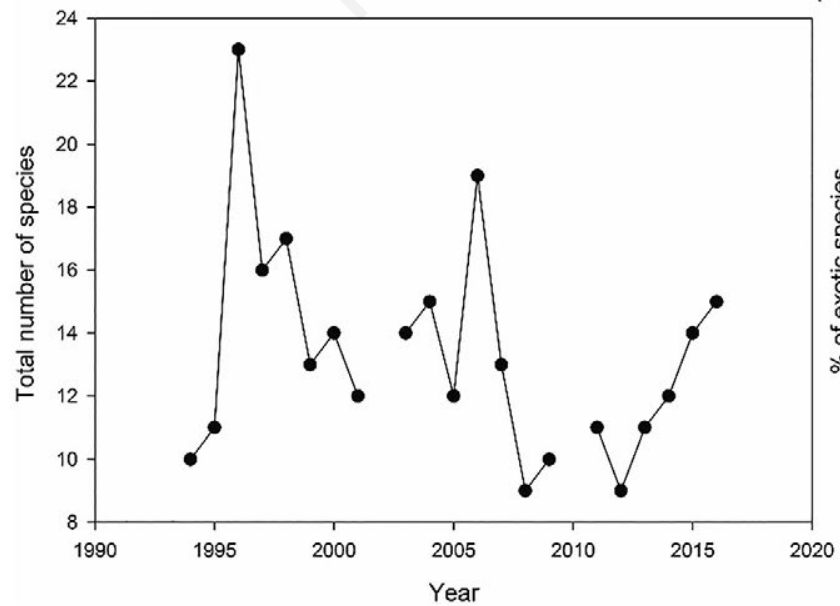

(a)

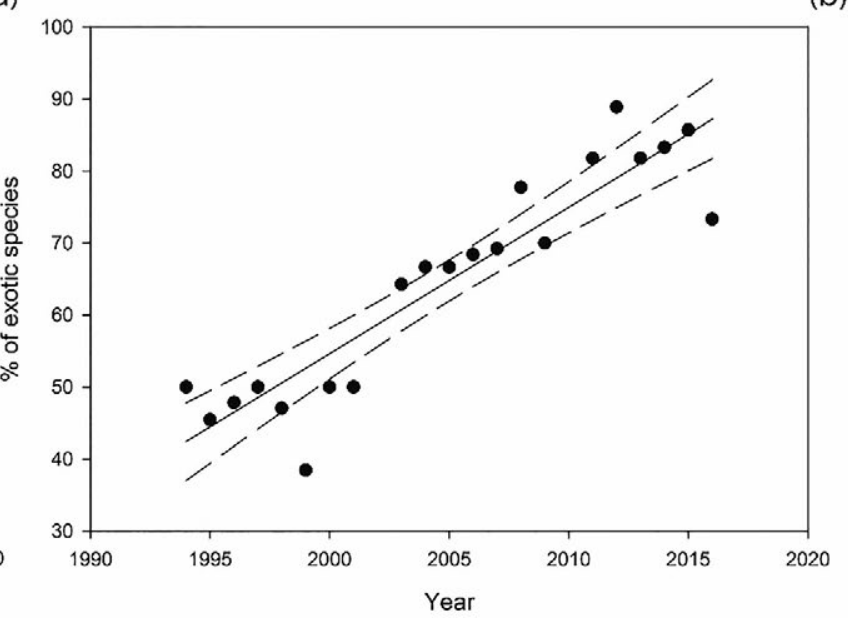

Fig. 4. Long-term trends in the total number of detected species (a) and the share of exotic species in the total (b). The solid line in (b) represents a significant linear regression while the dashed lines represent $95 \%$ confidence intervals. 
nested more strongly at the beginning of the period and progressively declined over time.

The results of RDA and nestedness analysis underlined numerous local extinctions in the native fish community of the lower Po River over the 20 -year period regardless of water temperature and discharge, while previous studies had found a relation between these abiotic variables and fish abundance or metrics (Daufresne and Boët, 2007; Daufresne et al., 2015). Although abundance or numerical data could be most useful in the assessment of species dynamics (Merten et al., 2010), such data could not be retrieved at the Berra plant because of the intensified interactions (such as predation) forced by confining fish for prolonged time periods in a small basin with low habitat complexity. Presence absence data was thus the best available option to study species successions, even if it did not allow to explore detailed population dynamics. While the long period considered was more than sufficient to assess longterm species dynamics, the effects of temperature increase on fish fauna were not clearly evident. Previous studies on climate change impacts on freshwater fauna suggest that a longer study period could be needed to detect temperature trends and their effects (Walther et al., 2002; Woodward et al., 2010), even if temperature trends were detected in another large river in northern Italy over a

Tab. 2. Nestedness of native and exotic species alone and the global rank considering all species (Overall).

\begin{tabular}{|c|c|c|c|}
\hline Nestedness order & Native & Exotic & Overall \\
\hline 1 & Anguilla anguilla & Cyprinus carpio & Anguilla anguilla \\
\hline 2 & Liza ramada & Carassius spp. & Cyprinus carpio \\
\hline 3 & Squalius squalus & Silurus glanis & Carassius spp. \\
\hline 4 & Alburnus arborella & Barbus barbus & Barbus barbus \\
\hline 5 & Chondrostoma soetta & Sander lucioperca & Liza ramada \\
\hline 6 & Scardinius hesperidicus & Abramis brama & Silurus glanis \\
\hline 7 & Perca fluviatilis & Leuciscus aspius & Sander lucioperca \\
\hline 8 & Leucos aula & Blicca bjoerkna & Abramis brama \\
\hline 9 & Acipenser naccarii & Ictalurus punctatus & Leuciscus aspius \\
\hline 10 & Salaria fluviatilis & Ctenopharyngodon idella & Blicca bjoerkna \\
\hline 11 & Rutilus pigus & Alburnus alburnus & Ictalurus punctatus \\
\hline 12 & Platichthys flesus & Pseudorasbora parva & Squalius squalus \\
\hline 13 & Esox cisalpinus & Lepomis gibbosus & Alburnus arborella \\
\hline 14 & Tinca tinca & Gymnocephalus cernuus & Chondrostoma soetta \\
\hline 15 & & Rhodeus amarus & Scardinius hesperidicus \\
\hline 16 & +0 & Rutilus rutilus & Ctenopharyngodon idella \\
\hline 17 & $\sqrt{-10+3}$ & Micropterus salmoides & Lepomis gibbosus \\
\hline 18 & & Ameiurus melas & Alburnus alburnus \\
\hline 19 & & Misgurnus anguillicaudatus & Perca fluviatilis \\
\hline 20 & & & Leucos aula \\
\hline 21 & & & Acipenser naccarii \\
\hline 22 & & & Gymnocephalus cernuus \\
\hline 23 & & & Pseudorasbora parva \\
\hline 24 & & & Rhodeus amarus \\
\hline 25 & & & Rutilus rutilus \\
\hline 26 & & & Platichthys flesus \\
\hline 27 & & & Rutilus pigus \\
\hline 28 & & & Salaria fluviatilis \\
\hline 29 & & & Micropterus salmoides \\
\hline 30 & & & Ameiurus melas \\
\hline 31 & & & Misgurnus anguillicaudatus \\
\hline 32 & & & Esox cisalpinus \\
\hline 33 & & & Tinca tinca \\
\hline
\end{tabular}


similar period (Salmaso et al., 2016). However, the trends revealed for the fish community could also be explained through other mechanisms not linked to discharge or temperature trends, namely the original environment adaptation of exotics and their human-mediated dispersal.

Most exotic species in our study area were native of East Europe, from rivers at higher latitudes and lower average water temperature than the Po River and not warm or tropical species as suggested by other authors (Bianco, 1998; Bianco and Ketmaier, 2001; Woodward et al., 2010; Daufresne et al., 2015). Therefore, warmer conditions in the host ecosystem could have substituted for warming trends and dispersal could have been partly human-enhanced (e.g. for those species relevant for recreational fisheries), although this aspect has never been thoroughly investigated. The rate of exotic species introduction is a phenomenon of global concern that affects freshwater communities as a whole (Nunes et al., 2015; Seebens et al., 2017), and the presence of these exotics was indeed the consequence of human activities, resulting in both unintentional (e.g. Ictalurus punctatus

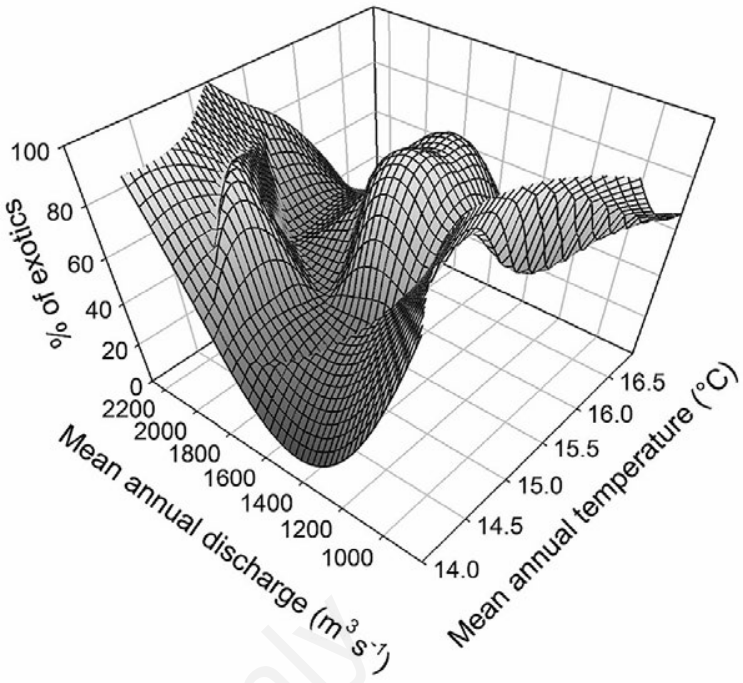

Fig. 5. Tridimensional mesh plot of the percentage of exotic species for different levels of mean annual discharge and temperature, showing no clear constant relation between these variables.

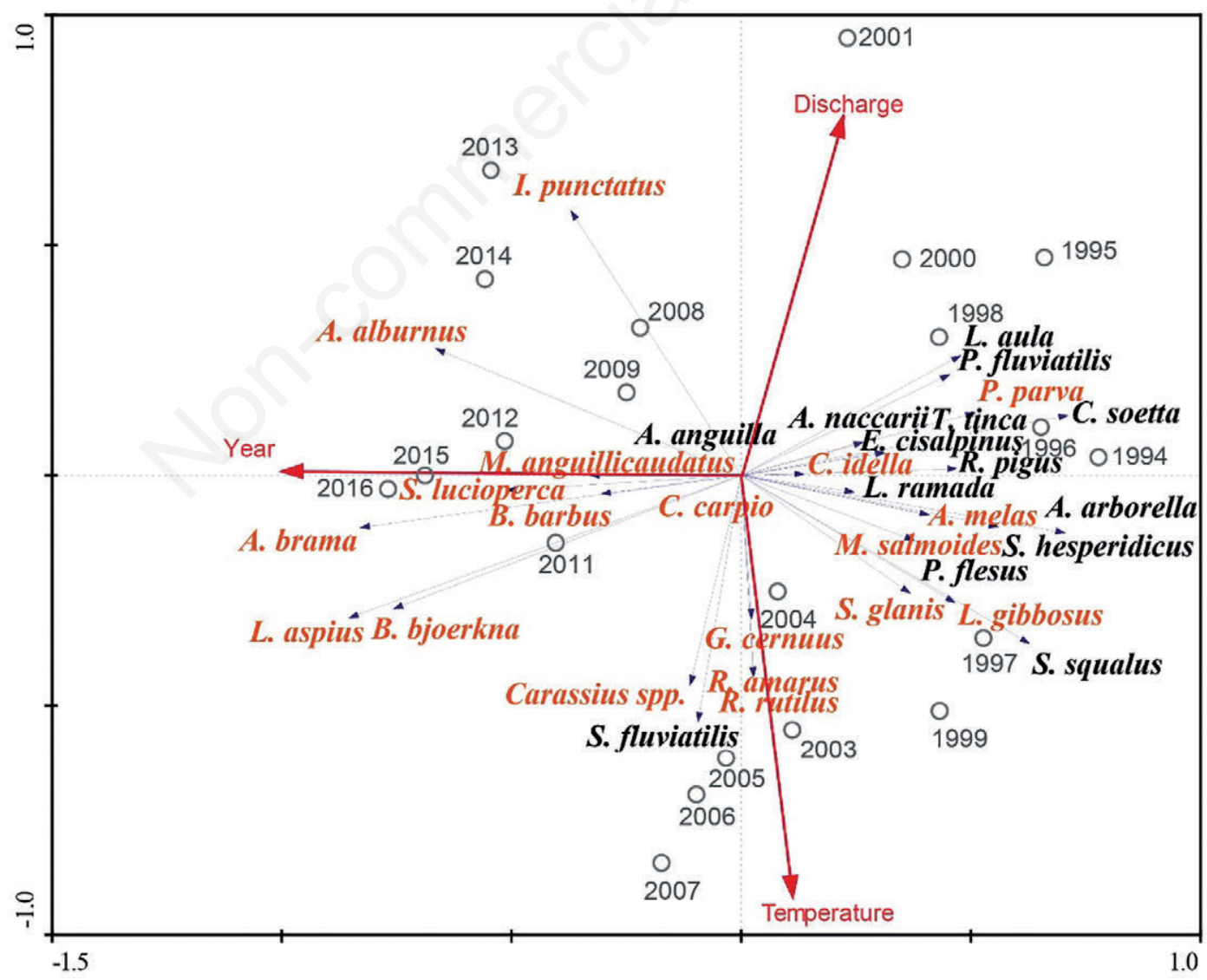

Fig. 6. RDA triplot showing the effects of time (year), discharge and temperature on the fish assemblages of the Berra plant. Sampling years indicated by gray hollow circles, native species by black and exotic species by orange scientific names. Please refer to Supplementary Tab. 1 for a list of full generic names. 
(Rafinesque, 1820) escaped from aquaculture) and intentional introductions (e.g. Abramis brama (Linnaeus, 1758) introduced for recreational fisheries or Ctenopharyngodon idella (Valenciennes, 1844) introduced for aquatic plant control (Milardi et al., 2015)). A mean of one new exotic species was recorded every three years from 1994 to 2016 in the lower Po River. However, the vast majority of exotic species in our data were detected several years after their introduction to this watershed and are therefore the result of dispersal and progressive invasion, rather than new introductions.

Despite wide fluctuations some of which clearly evident (in 1996 and 2008), the total number of species in our study area did not show a significant trend over time. Although this matter is controversial and largely debated (Herbold and Moyle, 1986; Olden and Rooney, 2006), our data suggested that the total number of species does not increase indefinitely in aquatic ecosystems when more species are added to the community, despite the low co-occurrence typical of fish communities (Gotelli and Ulrich, 2010). On the contrary, the rising share of exotic species indicates that the native fish species were progressively displaced by exotic ones. This could also be at the origin of the detected increase in temperature tolerant, benthivore and generalist species, as several exotics are considered such in the literature and were assigned to these ecofunctional categories. Similarly, the decrease in invertivores could be due to the decline of several native species, while a progressive substitution of native with exotic predators was also observed. Counterintuitively, the increase in rheophilic species (again mostly exotics) did not correspond to a trend in river discharge, but could perhaps still be due to smallscale changes in habitat availability within the river, which cannot be gauged by broad scale parameters. While fish ecofunctional niches tend to be broad (Milardi and Castaldelli, 2018), the rise in exotics could drive the overall changes in ecofunctional traits observed in the community. At this level, it was not possible to identify the respective roles of environmental and invasion factors, so further and more detailed analysis should be used to resolve this.

Besides being numerous, exotic species were particularly widespread and were previously found to be one of the most relevant factors negatively affecting the abundance and distribution of native fish communities of the lower Po River plain and its canal network (Castaldelli et al., 2013; Lanzoni et al., 2018; Milardi et al., 2018). However, due to the hydraulics of the siphons at Berra basin, some of these exotic fish have not been recorded in our data. Hypophtalmichthys spp., two pelagic planktivores present in the Po River and in the canal network (Milardi et al., 2017), were not captured. This is probably due to their very low density in the Po River and to their more epipelagic habits (Kolar et al., 2007), while the siphons draw water from a deeper water layer. However, we are confident that all other species present were sampled by the Berra siphons. In fact, species sampled at Berra plant were comparable with species found by other studies in nearby areas, where different sampling methods such as fishing nets or electrofishing were employed (Lanzoni et al., 2018).

\section{CONCLUSIONS}

Our data underlines a continuously rising tide of exotics, which questions the success of past control strategies. Past control actions for exotic fish species have faced numerous challenges: temporal and spatial discontinuity, a large area of intervention with a complex hydrographic network, the large overall exotic biomass and also the protests of some local anglers that defend exotic species. We would advise that future control actions should be coordinated between institutions at different spatial scales to be more effective. On the contrary, illegal fishing pressure targeting mainly exotic large size species (i.e. S. glanis and C. carpio) became widespread in the study area since 2010 (Milardi et al., 2015) and has probably had a significant impact on fish communities. The consequent decline of predation pressure from large-sized predators could be the reason behind the recolonization of the lower Po River and canal network by some native fish species (e.g. S. squalus or $A$. alborella, but careful consideration should be given to species determination as cryptic exotics, Squalius cephalus, L., and A. alburnus, could substitute native species and confound detection) but also by some previously less-common exotics (e.g. I. punctatus). Considering that conservation resources are limited and control management measures are usually expensive (Britton, Gozlan and Copp, 2011), priority should be given to the development of prevention strategies in order to avoid new species introductions. New and more effective strategies are now, more than ever, required.

\section{ACKNOWLEDGMENTS}

We thank the Fisheries Bureau of the Province of Ferrara and of the Emilia-Romagna Region for supporting the study in the context of a long-term research collaboration, and the Water Authority, namely the Consorzio di Bonifica Pianura di Ferrara, for providing the full support and all the facilities necessary for the access to the site and the recovery of the fish. The volunteers of the local association ARCI Pesca Ferrara are thanked for the positive collaboration and the work in recovering the fish. 


\section{REFERENCES}

Bianco PG, 1998. Freshwater fish transfers in Italy: history, local changes in fish fauna and a prediction on the future of native populations, p. 165-197. In: I. Cowx (ed.), Stocking and introductions of fishes. Fishing new book. Blackwell Science.

Bianco PG, 2014. An update on the status of native and exotic freshwater fishes of Italy. J. Appl. Ichthyol. 30:62-77.

Bianco PG, Ketmaier V, 2001. Anthropogenic changes in the freshwater fish fauna of Italy, with reference to the central region and Barbus graellsii, a newly established alien species of Iberian origin. J. Fish Biol. 59:190-208.

Bunn SE, Arthington AH, 2002. Basic principles and ecological consequences of altered flow regimes for aquatic biodiversity. Environ. Manage. 30:492-507.

Castaldelli G, Pluchinotta A, Milardi M, Lanzoni M, Giari L, Rossi R, Fano EA, 2013. Introduction of exotic fish species and decline of native species in the lower Po basin, northeastern Italy. Aquat. Conserv. 23:405-417.

Connor EF, Simberloff D, 1979. The assembly of species communities: chance or competition? Ecology 60:1132-1140.

Daufresne M, Boët P, 2007. Climate change impacts on structure and diversity of fish communities in rivers. Global Change Biol. 13:2467-2478.

Daufresne M, Veslot J, Capra H, Carrel G, Poirel A, Olivier JM, Lamouroux N, 2015. Fish community dynamics $(1985,2010)$ in multiple reaches of a large river subjected to flow restoration and other environmental changes. Freshwater Biol. 60:1176-1191.

Froese R, Pauly D, 2017. FishBase. Version 03/2017. Available from: www.fishbase.org

Gotelli NJ, Hart EM, Ellison AM, 2015. Co-occurrence analysis. EcosimR. Available from: http://ecosimr.org

Gotelli NJ, Ulrich W, 2010. The empirical Bayes approach as a tool to identify non-random species associations. Oecologia 162:463-477.

Hellmann JJ, Byers JE, Bierwagen BG, Dukes JS, 2008. Five potential consequences of climate change for invasive species. Conserv. Biol. 22:534-543.

Herbold B, Moyle PB, 1986. Introduced species and vacant niches. Am. Nat. 128:751-760.

Kolar CS, Chapman DC, Courtenay WR Jr, Housel CM, Williams JD, Jennings DP, 2007. Bigheaded carps: a biological synopsis and environmental risk assessment. American Fisheries Society, Bethesda: 204 pp.

Kottelat M, Freyhof J. 2007. Handbook of European freshwater fishes. Publications Kottelat: 646 pp.

Lanzoni M, Milardi M, Aschonitis V, Fano EA, Castaldelli G, 2018. A regional fish inventory of inland waters in Northern Italy reveals the presence of fully exotic fish communities. Eur. Zool. J. 85:1-7.

Leprieur F, Beauchard O, Blanchet S, Oberdorff T, Brosse S, 2008. Fish invasions in the world's river systems: When natural processes are blurred by human activities. PLoS Biol. 6:e28.

Leprieur F, Hickey M, Arbuckle C, Closs G, Brosse S, Townsend C, 2006. Hydrological disturbance benefits a native fish at the expense of an exotic fish. J. Appl. Ecol. 43:930-939.

Lepš J, Šmilauer P. 2003. Multivariate analysis of ecological data using CANOCO. Cambridge University Press.

Merten EC, Hemstad NA, Eggert S, Johnson L, Kolka RK,
Newman RM, Vondracek B, 2010. Relations between fish abundances, summer temperatures, and forest harvest in a northern Minnesota stream system from 1997 to 2007. Ecol. Freshw. Fish 19:63-73.

Milardi M, Aschonitis V, Gavioli A, Lanzoni M, Fano EA, Castaldelli G, 2018. Run to the hills: exotic fish invasions and water quality degradation drive native fish to higher altitudes. Sci. Total Environ. 624:1325-1335.

Milardi M, Castaldelli G, 2018. A novel approach to an ecofunctional fish index for Mediterranean countries. Ecol. Indic. 89C:376-385.

Milardi M, Chapman D, Lanzoni M, Long JM, Castaldelli G, 2017. First evidence of bighead carp wild recruitment in Western Europe, and its relation to hydrology and temperature. PloS One 12:e0189517.

Milardi M, Lanzoni M, Kiljunen M, Torniainen J, Castaldelli G, 2015. Natural recruitment contributes to high densities of grass carp Ctenopharyngodon idella (Valenciennes, 1844) in Western Europe. Aquat. Invasions 10:439-448.

Moyle PB, Light T, 1996a. Biological invasions of fresh water: empirical rules and assembly theory. Biol. Conserv. 78:149-161.

Moyle PB, Light T, 1996b. Fish invasions in California: do abiotic factors determine success? Ecology 77:1666-1670.

Nunes AL, Tricarico E, Panov VE, Cardoso AC, Katsanevakis S, 2015. Pathways and gateways of freshwater invasions in Europe. Aquat. Invasions 10:359-370.

Olden JD, Rooney TP, 2006. On defining and quantifying biotic homogenization. Global Ecol. Biogeogr. 15:113-120.

R Core Team, 2017. R: A language and environment for statistical computing. Vienna. Available from: www.R-project.org

Rahel FJ, Olden JD, 2008. Assessing the effects of climate change on aquatic invasive species. Conserv. Biol. 22: 521-533.

Rodríguez-Gironés MA, Santamaría L, 2006. A new algorithm to calculate the nestedness temperature of presence-absence matrices. J. Biogeogr. 33:924-935.

Salmaso F, Quadroni S, Gentili G, Crosa G, 2016. Thermal regime of a highly regulated Italian river (Ticino River) and implications for aquatic communities. J. Limnol. 76:23-33.

Schmidt-Kloiber A, Hering D, 2015. www. freshwaterecology.info - An online tool that unifies, standardises and codifies more than 20,000 European freshwater organisms and their ecological preferences. Ecol. Indic. 53:271-282.

Seebens H, Blackburn TM, Dyer EE, Genovesi P, Hulme PE, Jeschke JM, Pagad S, Pyšek P, Winter M, Arianoutsou M, 2017. No saturation in the accumulation of alien species worldwide. Nature Comm. 8:14435.

Strayer DL, Eviner VT, Jeschke JM, Pace ML, 2006. Understanding the long-term effects of species invasions. Trends Ecol. Evol. 21:645-651.

Ter Braak CJ, Smilauer P, 2002. CANOCO reference manual and CanoDraw for Windows user's guide: software for canonical community ordination (version 4.5). Available from: www.canoco.com

Walther G-R, Post E, Convey P, Menzel A, Parmesan C, Beebee TJ, Fromentin J-M, Hoegh-Guldberg O, Bairlein F, 2002. Ecological responses to recent climate change. Nature 416:389-395.

Woodward G, Perkins DM, Brown LE, 2010. Climate change and freshwater ecosystems: impacts across multiple levels of organization. Phil. T. R. Soc. B 365:2093-2106. 